\title{
Redescription of the Male of Lutzomyia lutziana(Costa Lima) and Description of the Female (Diptera: Psychodidae)
}

\section{José Dilermando Andrade Filho/+, Alessandra Gutierrez de Oliveira*, Alda Lima Falcão, Reginaldo Peçanha Brazil}

\author{
Centro de Pesquisas René Rachou-Fiocruz, Av. Augusto de Lima 1715, 30190-002 Belo Horizonte, MG, Brasil \\ *Centro de Controle de Zoonoses, Secretaria Municipal de Saúde, Campo Grande, MS, Brasil
}

\begin{abstract}
During the course of taxonomic studies of New World phlebotomine sand flies, it was discovered that the female specimen considered to be the female of Lutzomyia lutziana does not belong to this species. A new description of the female of L. lutziana is presented, based on specimens captured in Lassance, State of Minas Gerais, the type locality of the species. The male of L. lutziana is also redescribed, based on an exemplar caught in Curvelo, State of Minas Gerais.
\end{abstract}

Key words: Lutzomyia lutziana - Phlebotominae - sand fly - taxonomy - Brazil

During the course of studies on the taxonomy of New World phlebotomine sand flies it was discovered that the female specimen considered by Forattini (1973), Léger et al. (1977) and Martins et al. (1978) as being conspecific with the Phlebotomus sp. from Cayenne, partially described by Floch and Abonnenc (1945), is not the allotype of Lutzomyia lutziana (Costa Lima). In the original description of Phlebotomus sp. from Cayenne (Floch \& Abonnenc 1945) the common duct is longer than the individual duct, whereas in the drawing of the female of L. lutziana shown in Young and Duncan (1994; Fig. 139 J) the common duct is shorter than the individual duct. Based on the examination of two females of L. lutziana captured in the type locality of Lassance (17053'12' S; 44034'39' W), State of Minas Gerais (MG), Brazil, and housed in the slide collection of the Centro de Pesquisas René Rachou-Fiocruz in Belo Horizonte it is concluded that Phlebotomus sp. of Cayenne is not the female of this species.

Costa Lima's (1932) description of the male is incomplete, and following the discovery and formal description of L. campograndensis Oliveira Andrade Filho Falcão and Brazil 2001, a morphologically similar species, it was decided to redescribe the male of L. lutziana. The male chosen to this description was collected at Curvelo (18 45'23"S; 44²5'51' W), approximately $90 \mathrm{~km}$ from the original type locality of Lassance and an area which presents the same ecological conditions.

The description is based on characters proposed by the Cipa group (1990) and Galati (1995).

\section{REDESCRIPTION OF MALE}

Figs 3 and 4

(all measurements in $\mathrm{mm}$ )

Total length 2995. Head and notum light brown, pleurae and coxae paler than notum.

This work was supported by $\mathrm{CNPq}$, Fiocruz, Funasa and Sesau/ Campo Grande

${ }^{+}$Corresponding author. Fax +55-31-3295.3566. E-mail: jandrade@cpqrr.fiocruz.br

Received 23 May 2001

Accepted 5 November 2001
Head: length 0.255 , not including the clypeus of length 0.104 . Ratio head/clypeus 2.45: 1 . Inter-ocular distance 0.086. Labrum length 0.186 . Lengths of palpomeres: 1 $0.028 ; 2$ - $0.079 ; 3$ - 0.121; 4 - 0.069; 5 - 0.190. Palpal formula 1.4.2.3.5. Fifth palpomere equal in length to palpomeres 3 +4 and shorter than palpomeres $2+3+4$. Newstead's spines present on palpomere 3. Antennae with ascoids absent on AXIV, AXV and AXVI. Proximal prolongation of ascoids short, not reaching the base of the flagellomere. Distal prolongation long, extending to next flagellomere. External ascoids situated more distally than internal ones on AIII- AXIV. Papillae present on segments AIV, AV, AXIII-AXVI. Length of flagellomere AIII - 0.307; AIV 0.169; AV - 0.173. AVXV longer than AXVI. Ratio AIII/LE 1.65: 1.

Ventrocervical sensillae absent from cervix.

Thorax: notum light brown. Pleurae and legs paler than notum. Hind femur longer than fore femur, respective lengths 0.937 and 0.908 . Middle femur lost during the preparation and not mounted. Maximum wing breadth 0.695 . Length of principal wing sections: $\alpha(\mathrm{R} 2)-0.724 ; \beta(\mathrm{R} 2+3)$ - 0.284; $\gamma(\mathrm{R} 2+3+4)-0.270 ; \delta$ (part of R1 extending beyond junction of R2 + R3) - 0.241; R5 - 1.377

Abdomen: coxite length 0.366, without tuft of cerdae. Style of length 0.214 and bearing four strong spines, one of them being apical, one intermediate inserted on a process and two inserted on different levels on the basal third of structure. Subterminal setae absent. Paramere simple, broader at base, tapered in the middle and expanded distally, with a distal group of setae present. Lateral lobe extends beyond coxite, length 0.459 . Aedeagus large and with a broad tip. Genital pump length 0.159 . Genital filaments measuring 0.362 , lightly grooved and with simple tips, maximum width 0.004 . Ratio genital filaments/genital pump 2.10: 1 .

\section{DESCRIPTION OF FEMALE}

Figs 1-3

(in parentheses measurements of paratype)

Allotype: coloration similar to that of male.

Head: length 0.280 (0.269), not including clypeus of length 0.110 (0.107). Ratio head/clypeus 2.55:1 (2.51:1). Inter-ocular distance 0.90 (0.093). Labrum length 0.197 


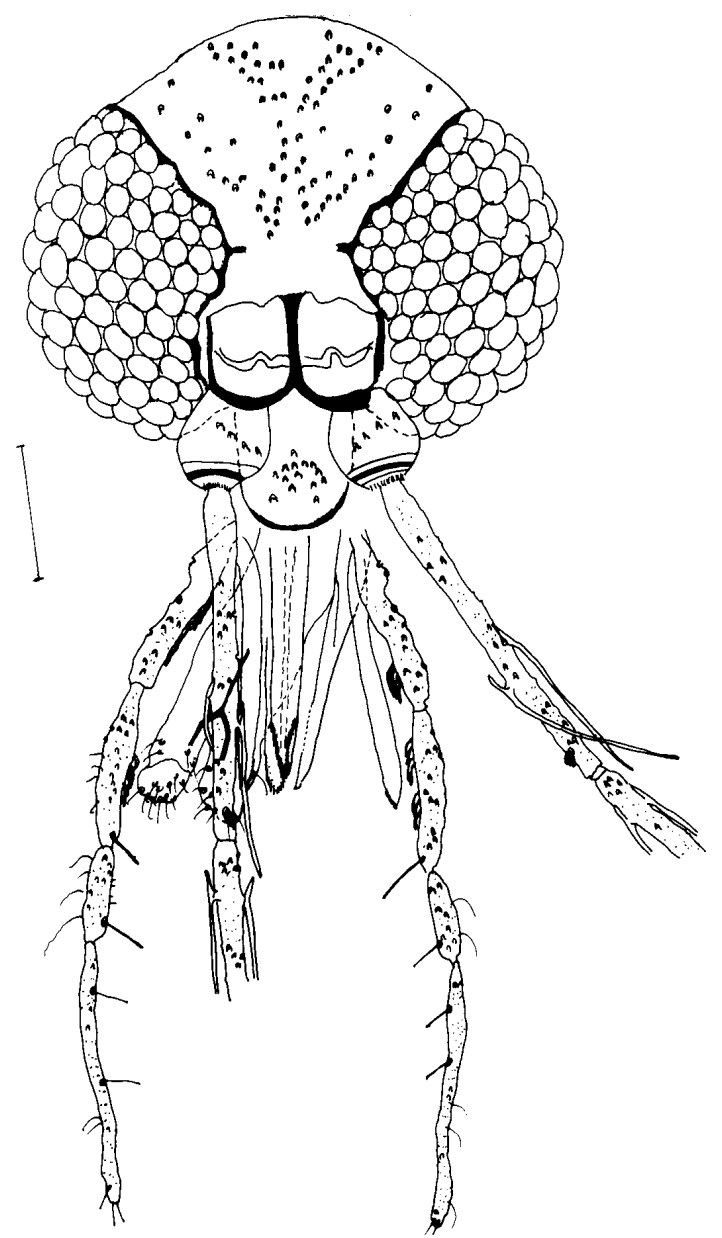

Lutzomyia lutziana - Fig. 1: head (allotype). Bar: $100 \mu \mathrm{m}$

(0.193). Maxilla with a row of external longitudinal teeth. Length of palpomeres: $1-0.035(0.038) ; 2-0.090(0.086) ; 3$ - 0.128 (0.117); 4 - 0.069 (0.066); 5 - 200 (0.186). Palpal formula 1.4.2.3.5. (1.4.2.3.5). Fifth palpomere shorter than 3rd +4 th. Newstead's spine present on palpomere 3 . Ascoids absent on AXV and AXVI, proximal prolongation short and distal prolongation long, extending to next flagellomere. External ascoids situated more distally than internal ones on AIII-AXIV. Papillae present on segments AIV, AV, AXIII -AXVI. Length of flagellomere AIII-0.276 (0.311); AIV- 0.145 (0.142); AV-0.145 (0.155). AXV longer than AXVI. Cibarium with four small horizontal teeth and irregular orientation. Vertical teeth arranged on the pigment patch of cibarium. Cibarial arch complete with prominent pigment patch. Pharynx unarmed.

Ventrocervical sensillae absent from cervix.

Thorax: as in male. Fore femur length 0.979 (0.908). Middle and hind legs lost during the preparation and not mounted. Maximum breadth of wing $0.766(0.752)$. Length of principal wing sections: $\alpha(\mathrm{R} 2)-0.724(0.724) ; \beta(\mathrm{R} 2+3)$ $-0.227(0.241) ; \gamma(\mathrm{R} 2+3+4)-0.185(0.199) ; \delta($ part of R1 extending beyond junction of R2 + R3) - $0.284(0.312)$; R5 - 1.377 (1.405).

Abdomen: cercus simple, length 0.159 (0.176). Spermathecae spherical, length 0.017 (0.017) width 0.031 (0.028).
Head of spermathecae barely visible. Individual ducts with a more heavily sclerotized region of length 0.024 (0.028). Individual duct length 0.079. Common ducts length 0.035 .

Collection data and deposition of material: male collected by R Diniz at Fazenda São Sebastião, municipality of Curvelo, MG, on 16 September 1958, number 6493. Allotype female collected by JD Andrade Filho and RP Brazil at Fazenda São Gonçalo, municipality of Lassance, MG, Brazil, on 8 July 1997, number 75.509, together with one female paratype, number 75.508 . All three specimens deposited in the phlebotomine sand fly collection of the Centro de Pesquisas René Rachou-Fiocruz, Belo Horizonte, MG.

\section{REMARKS}

According to Young and Duncan (1994), L. lutziana belongs provisionally to the subgenus Psathyromyia Barretto. The female described by Floch and Abonnenc,
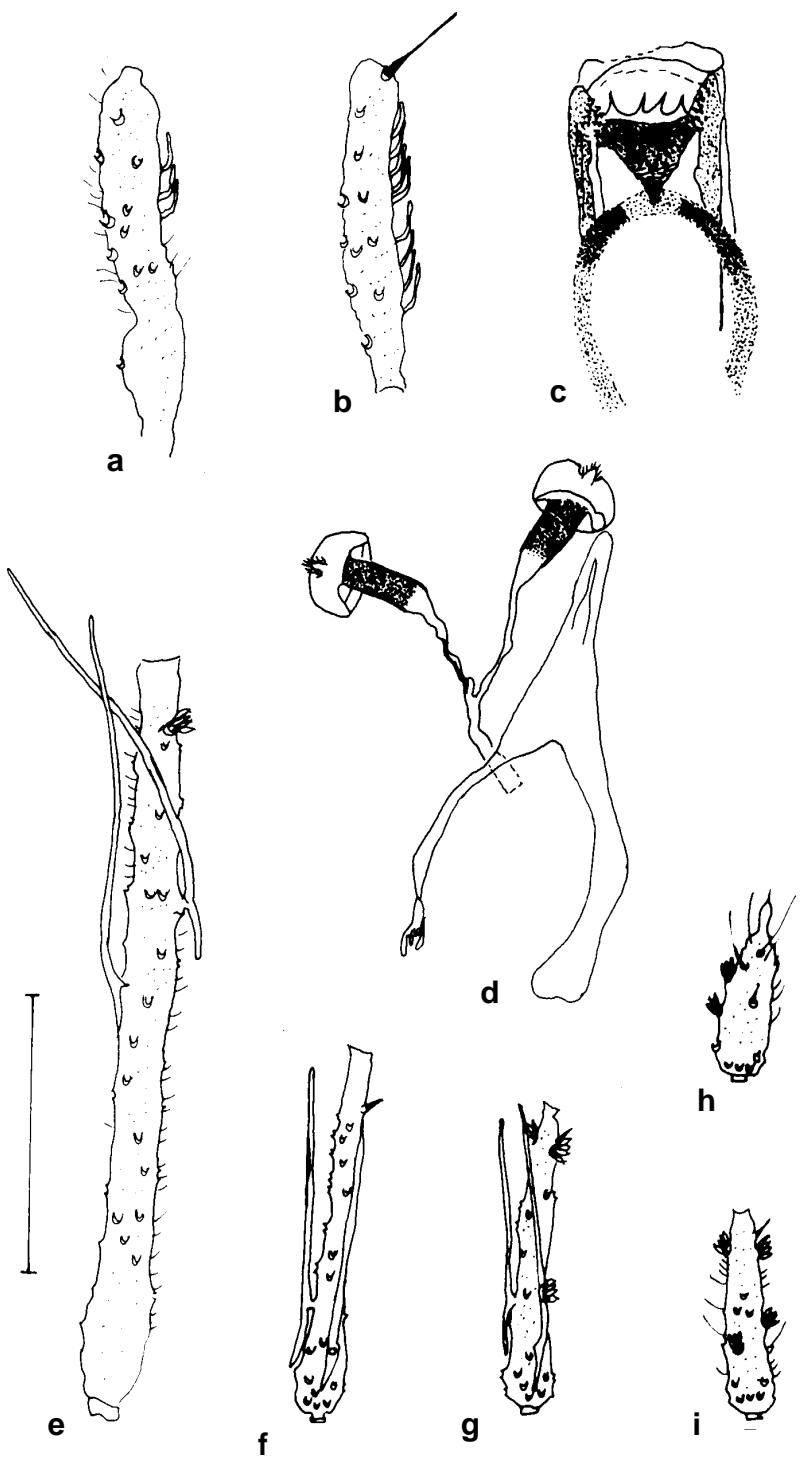

Fig. 2: Lutzomyia lutziana - a: 1st and 2nd palpomeres (allotype); b: 3rd palpomere (allotype); c: cibarium (allotype); d: spermathecae (allotype); e: AIII (allotype); f: AXIII (paratype); g: AXIV (paratype); h: AXV (paratype); i: AXVI (paratype). Bar: $100 \mu \mathrm{m}$ 


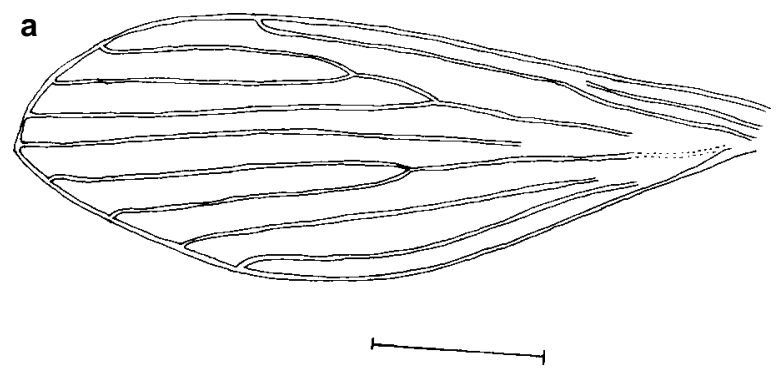

b

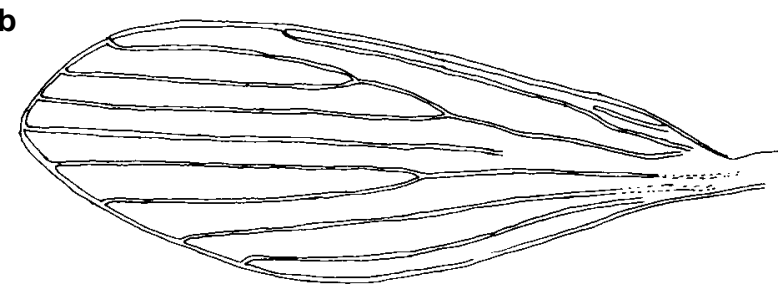

Fig. 3: Lutzomyia lutziana - a: wing (allotype); b: wing (male). Bar: $500 \mu \mathrm{m}$

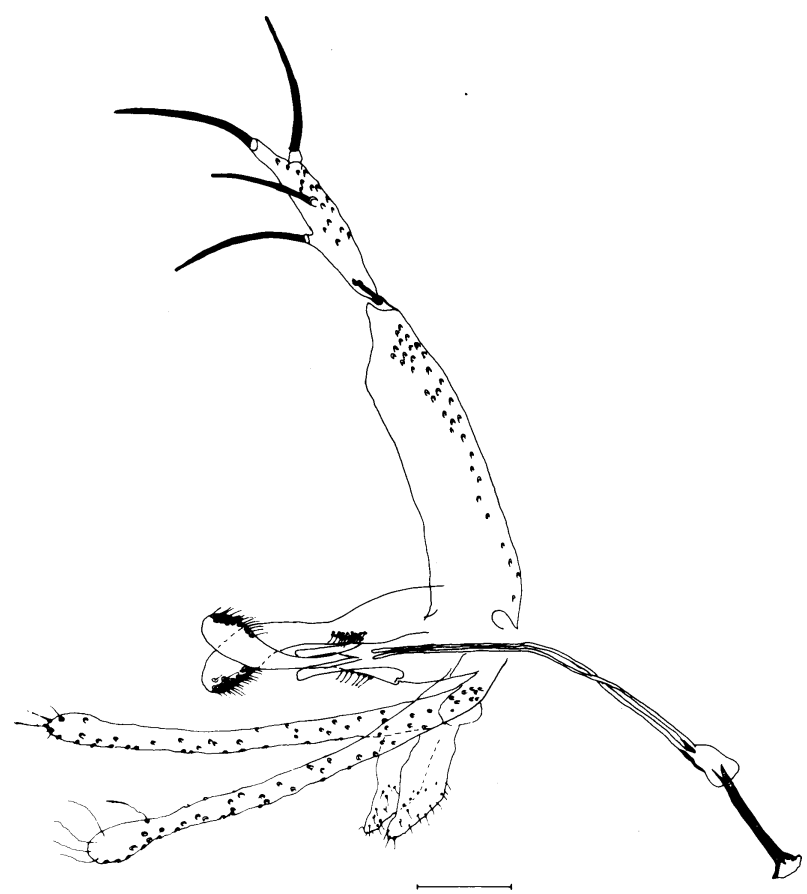

Fig. 4: Lutzomyia lutziana - genitalia (male). Bar: $100 \mu \mathrm{m}$

in 1945 , is not definitively the female of L. lutziana. Although Young and Duncan (1994) showed a female that is more close to the female described by us, they did not give any further information to be included as a formal described female of $L$. lutziana.
The shape of the paramere and aedeagus separates the male of L. lutziana from those of other species. The appearance of the female spermathecae is also distinctive. The species most similar to L. lutziana is L. campograndensis, recently described from Campo Grande, Mato Grosso do Sul, Brazil (Oliveira et al. 2001). The males can be separated based on the tips of genital filaments, these being dilated in L. campograndensis and $0.010 \mathrm{~mm}$ wide, more than twice as broad as those of L. lutziana $(0.004$ $\mathrm{mm})$. The ratio of the lengths of the genital filaments/ genital pump can also be used to distinguish the species. In $L$. lutziana this ratio is greater that 2.10, while in $L$. campograndensis it is less than 1.90 . The female spermathecae of $L$. lutziana are smaller than those of the other species, and the ratio individual duct/common duct is 2.26 in L. lutziana and 1.30 in L. campograndensis.

According to the classification of Galati (1995) $L$. lutziana belongs to the genus Psathyromyia Barreto 1962, subgenus Forattiniella Vargas 1978 and series lutziana. In addition to L. lutziana and L. campograndensis, this series also includes L. pascalei (Coutinho \& Barretto). This last species can be separate from $L$. lutziana by the longer proximal prolongation of its ascoids and by the appearance of the male terminalia. The female of the two species are easily distinguished based on the forms of the cibarium and spermathecae.

\section{REFERENCES}

Cipa Group Bermudes H, Dedet JP, Falcão AL, Feliciangeli D, Ferro C, Galati EAB, Gomes EL, Herrero MV, Hervas D, Lebbe J, Morales A, Oguzuku E, Perez E, Rangel EF, Sherloch IA, Torres M, Vignes R, Wolff M 1991. Proposition of a standard description for phlebotomine sand flies. Parassitologia 33 (Suppl.): 127-135.

Costa Lima A 1932. Sobre os phlebotomos americanos (Diptera: Psychodidae) Mem Inst Oswaldo Cruz 26: 15-59.

Floch H, Abonnenc E 1945. Phlebotomes de la Guyane Française (XIII) Description de deux nouvelles femelles. Inst Pasteur Guyane 98: 1-4.

Forattini OP 1973. Entomologia Médica. Psychodidae. Phlebotominae. Leishmanioses. Bartonelose, Vol. 4, Edgar Blücher Ltda., São Paulo, 658 pp.

Galati EAB 1995. Phylogenetic systematics of Phlebotominae (Diptera, Psychodidae) with emphasis on American groups. Bol Dir Malariol San Amb 35 (Supl. 1): 133-142.

Léger N, Abonnenc E, Pajot FX, Kramer R, Clautre J 1977. Liste commentée des phlébotomes de la Guyane Française. Sér Ent Méd Parasitol 3: 217-232.

Martins AV, Williams P, Falcão AL 1978. American Sand Flies (Diptera: Psychodidae, Phlebotominae), Acad Bras Ciências, Rio de Janeiro, 195 pp.

Oliveira AG, Andrade Filho JD, Falcão AL, Brazil RP 2001. A new sand fly, Lutzomyia campograndensis sp. n. (Diptera: Psychodidae: Phlebotominae) from the State of Mato Grosso do Sul, Brazil. Mem Inst Oswaldo Cruz 96: 325-329.

Young DG, Duncan MA 1994. Guide to the identification and geographic distribution of Lutzomyia sandflies in Mexico, the West Indies, Central and South America (Diptera: Psychodidae). Mem Am Entomol Inst 54: 1-881. 
Lutzomyia lutziana • José Dilermando Andrade Filho et al. 